\title{
LA BESTIA NEGRA DE TODO TEORIA DE LA JUSTICIA
}

\section{THE BLACK BEAST IN EVERY THEORY OF JUSTICE}

Fecha de recepción: 10/3/18 Fecha de aceptación: 6/4/18

\section{Gabriela Rodríguez}

Practicante del Psicoanálisis. Asociada a la Escuela de Orientación Lacaniana (EOL) Sección - La Plata. Integra el Consejo Editorial de la Revista Estrategias -Psicoanálisis y salud mental-. Autora de numerosos artículos en revistas especializadas
Resumen: Un extraño antagonista sale al paso en la argumentación de la teoría de la justica de John Rawls cuando intenta excluir a la envidia de su sistema de justicia, se trata de Sigmund Freud quién encuentra envidia transformada a la base de la pasión igualitaria que nutre los sentimientos de justicia, minando los argumentos que sostiene la ficción original de la empresa rawlsiana.

Palabras claves: Justica - Envidia - Pasión igualitaria - Sacrificio - Goce.

En un ensayo (1) dedicado a examinar el vínculo entre justicia y envidia auscultado por el psicoanálisis, John Forrester se descubre totalmente ciego a una lectura de la conocida parábola del rey Salomón, que se lee en el Libro I de los Reyes, de la Biblia. Se recordará, se trata del litigio entre dos mujeres que dicen ser la verdadera madre de un niño y que vienen ante el sabio de Salomón a que dictamine sobre la disputa, episodio del que surgirá lo que se conoce con el nombre de decisión o juicio salomónico. Forrester repasa dos de las lecturas habituales, una que se detiene en la astucia del rey que escapa al engaño valiéndose de un artilugio contrario a su objetivo, cortar al niño en dos pedazos para satisfacer a las mujeres y así descubrir, ante la negativa de una de ellas, cuál de las dos es la verdadera madre - lectura que califica como "lección zen" -, otra que pone de relieve la abnegación conmovedora de la madre que renuncia al reclamo de su amado hijo para preservar su vida antes que su tener contra el reclamo
Abstract: It is Freud who appeared as a strange antagonist in the discussion about Rawlsian theory of justice when trying to exclude envy from its justice system. He found the transformed envy at the base of the equalizing passion that nurtures feelings of justice and so he destroyed the grounds supporting the original fiction of Rawls' enterprise.

Key words: justice, envy, equalizing passion, sacrifice, pleasure egoísta de la otra mujer - lectura idealizante del amor materno -

La ceguera de Forrester tropieza con una tercera lectura, hallada en Psicología de las masas y análisis del yo (2), donde Freud a su paso por la consideración del instinto gregario descubre el origen non santo del llamado espíritu comunitario en la "envidia originaria". El argumento freudiano revela como el sentimiento de justicia no es más que la primera exigencia surgida de la formación reactiva que se produce por confrontación del niño pequeño con la llegada de un hermano al que querrá desalojar para ser el único beneficiario del amor de los padres, pero que, en vistas de conservar ese mismo amor, consiente al abandono de la actitud hostil y se identifica con otros, a condición de recibir igual trato para todos, una circunstancia que instalará además, la pasión igualitarista. Casi al final del apartado Freud sentencia: "Igual núcleo tiene la bella anécdota del fallo de Salomón. Si el hijo de una de las mujeres 
ha muerto, tampoco la otra ha de tenerlo vivo" (3), a lo que Forrester agrega: el acento puesto por Freud en la mujer que mantiene su reclamo: "no será ni para mí ni para ti, que lo partan" -que tiene un apoyo textual en la Biblia-, muestra el papel de motor fundamental que puede asumir la envidia a la base del reclamo igualitario en el que descansa el elevado ideal de justicia, justicia que no será ni "redistributiva", ni mucho menos "impersonal", sino ligada a una lógica de hierro que establece: partes iguales para iguales sujetos. En esta última puntuación en la que Forrester apunta contra el carácter redistributivo e impersonal de todo ideal de justicia, leemos una alusión a John Rawls, de hecho, en lo que sigue, el ensayo se dedicara a examinar "una exposición reciente sobre la justicia que ha ejercido mayor influencia, la de John Rawls". Así es que, por la vía de considerar las lecturas del episodio bíblico que entroniza la sabiduría del Rey Salomón, nos encontramos de lleno en el terreno de los problemas que se suscitan en la filosofía política, precisamente toda vez que se trate de la formulación de una teoría de la justica. El mencionado John Rawls en su Teoría de la justicia de 1971 (4), se verá obligado a hacer entrar a Freud en su argumentación, con miras a calibrar el surgimiento de los sentimientos morales, expediente necesario para el sostenimiento estable del sistema de justicia en una comunidad, no obstante, y como se verá, será el factor de la envidia elucidado por Freud, contrario en apariencia a los sentimientos morales el que se ganará un desarrollo particular. Rawls reseña dos tradiciones a este respecto, la primera que se extrae de la doctrina empirista y que leemos en los utilitaristas, la segunda que se deriva del pensamiento racionalista y que se traduce en un naturalismo, colocando a Freud entre los primeros. Cabe aclarar que desde el comienzo el esfuerzo rawlsiano se dirige a ofrecer una explicación sistemática superadora en su elaboración de la teoría de la justicia del utilitarismo dominante. Rawls lee en clave utilitarista la elaboración freudiana de la justicia como dependiente de la formación reactiva por la cual se ceden los sentimientos hostiles, la envidia, a cambio del trato igualitario, lo que traería un beneficio propio y al fin y al cabo consolidaría una utilidad para la sociedad toda. Freud ocupará el lugar de un antagonista privilegiado en el apartado dedicado a examinar las posibles conexiones entre envidia e igualdad (5), entre otros autores Freud también habría puesto de relieve que la tendencia a la igualdad en los movimientos sociales modernos es expresión de la envidia.

"Para demostrar que los principios de la justicia se basan, en parte, en la envidia [sostiene Rawls], habría que probar que una o más de las condiciones de la situación original surgen de esta propensión". La llamada "posición original" (6) refiere a una situación utópica inventada por Rawls que se propone como un "experimento mental", tendiente a reflejar con la mayor fidelidad posible la situación imaginaria en la que los integrantes libres de una sociedad se encuentran frente a la tarea de definir y así darse por elección, un ideal de justicia, asentando con ello los principios de una justicia ideal, principios que se podrían abreviar del siguiente modo: iguales en libertad / cooperación mutua voluntaria. Como ha sido señalado por Nestór Brausntein (7) la ficción rawlsiana de la posición original, contrapartida tranquilizante al mito freudiano de la horda primitiva, se desvanece como un sólido en el aire con solo inyectarle lo real del malestar en la cultura y sus tres fuentes presentadas por Freud como: el poder de la naturaleza, la caducidad de nuestro cuerpo, y paradójicamente el imposible para lo que la situación original se inventa como un remedio, la regulación de las relaciones sociales generadora de una hostilidad irreductible. Rawls prosigue: "Naturalmente, puede haber formas de igualdad que surjan de la envidia. El igualitarismo estricto, la doctrina que insiste en una distribución igual de todos los bienes primarios, acaso se derive de esta propensión. Esto significa que tal concepción de la igualdad sólo se habría adoptado en la situación original suponiendo que los individuos fuesen suficientemente envidiosos. Esta posibilidad no afecta, en modo alguno, a los dos principios de la justicia. La concepción diferente de la igualdad que ellos definen se admite sobre el supuesto de que la envidia no existe" (8).

A confesión de parte... como reza el axioma jurídico, eliminar la envidia como elemento insidioso de la "situación originaria" garantiza para Rawls mantenerse a salvo de la "lógica de hierro" diría Forrester, lo irrestricto de la pasión igualitaria que como la justicia absoluta haría temblar el mundo - Lacan dixit -. Pero su diseño de la situación social que somete a la voluntad y el arbitrio racional de unos hombres los asuntos 
de justicia requerirá por tal motivo del llamado "velo de ignorancia" (9), para neutralizar lo que en la situación podría parecer como coacciones externas surgidas de la historia individual, los privilegios o atributos personales que puedan introducir diferencias y/o desigualdades, sean estas debidas a la naturaleza o al componente social. Es decir, como el propio Rawls lo expresa se trata de que "los resultados del azar natural o de las contingencias de las circunstancias sociales no den a nadie ventajas ni desventajas al escoger los principios". El "velo de ignorancia" que se tiende sobre los integrantes de aquella situación, y que hace las veces de ceguera respecto del: sexo, la raza, el origen social, la distribución de la fuerza, la riqueza, la belleza, la inteligencia, reintroduce en la situación la consecuencia indeseada, la pasión igualitaria, que es ahora también la de Rawls. Siendo la ceguera correlativa del velo de ignorancia, introduce además "la huella de un buen ojo, un ojo que bendice" (10), que claro está es un ojo necesariamente ciego, por estar desanexado de su "función mortal" la que lo dota de un poder separador, “'habrá mejor imagen de ese poder que la invidia?, ironiza Jacques Lacan valiéndose de la etimología, invidia que viene de videre. La envidia así excluida aparece como el anverso del "velo de ignorancia".

Otro de los modos -lo que se diría escapar por la tangente- que encuentra Rawls en su cruzada contra el papel central de la envidia, será imputar a Freud una confusión entre envidia y resentimiento. Rawls explica que "la creencia general en que la suma de la riqueza social es más o menos fija, de modo que lo que una persona gana es lo que otra pierde" (11), se equivoca al considera al sistema social como un juego de suma cero, establecido e invariable. La extensión de esta creencia en el volumen fijo de bienes nos lleva a admitir la prevalencia estricta de oposición de intereses, a costa de excluir, sostiene el bueno de Rawls, el hecho de que la riqueza puede ser la consecuencia de una cooperación mutua beneficiosa. Por ese motivo sostendrá que lo que se llama envidia, mal fundada en esta creencia no es otra cosa que resentimiento, y "las especulaciones de Freud acerca del origen del sentido de la justicia adolecen del mismo defecto", en lo que sigue pondrá en marcha una pequeña operación comparativa. La situación original freudiana cuyo paradigma podría ser la situación de la "guardería infantil", con pocos cambios, se corresponde con la posición original que él mismo inventará (12), asegura el filósofo, las diferencias entre los niños lejos de ser impulsadas por la envidia surgen ahora del resentimiento fundado en la sensación de que están siendo injustamente tratados, razón por la cual, Rawls privilegiará la necesidad de atender a las concepciones de la justicia sostenidas por los individuos, siempre dependientes de la comprensión de la situación social, para así poder determinar en qué motivos se fundan estas tales aspiraciones. No obstante, la evidente confianza en que la compresión correcta de la situación podrá traducirse en una concepción justa de lo que es justo, de por si objetable, el argumento es rematado con la siguiente aclaración: "Ninguna de estas observaciones pretende negar que la apelación a la justicia sea, muchas veces, una máscara para la envidia" (13).

El esfuerzo de Rawls por conjurar el peligro de la envidia como elemento irracional que mina su sistema es puesto en foco por Jean Pierre Dupuy en El sacrificio y la envidia. La justicia social y el liberalismo (14) comentado in extenso por Germán García en su "Curso de las pasiones" de 1999 (15). La envidia o la bestia negra de toda teoría de la justicia, dice Dupuy citado por García, se introduce como sospecha siempre que se pretende hablar en nombre de la justicia, "Rawls lo sabe demasiado bien [de allí que no descuide el argumento freudiano]. Él [ironiza Dupuy] que a menudo ha sido objeto de esa agresión ética por parte de sus colegas liberales". Para Dupuy, estudioso de Rawls que abre el camino en Francia para la primera traducción de Teoría de la Justicia, los problemas que suscita la envidia hacen que el sistema de Rawls sea sumamente inestable, $y$, por consiguiente, sin posibilidad de evitar un correlato combatido por el propio Rawls, la pendiente altamente sacrificial. Punto central este, de su disputa con los utilitaristas cuando rechaza que "los sacrificios impuestos a unos sean compensados por la mayor cantidad de ventajas disfrutadas por muchos". De tal pendiente, Rawls se protege so pretexto del primer principio de la justica abreviado como "de los iguales en libertad". $\mathrm{Al}$ igual que con la envidia, la empresa rawlsiana cabalmente kantiana vacía de todo objeto de interés patológico los principios de justicia, lo que representa de algún modo el sacrificio del bien por lo justo, del particularismo por lo igualitario. 
De los tipos de envidia descriptos por Rawls, la envidia general en la que los menos favorecidos desean las posiciones de otros más favorecidos y las envidias particulares, que espejan los deseos de las posiciones/posesiones de las personas consideradas rivales, Dupuy se detiene en el último en clave stendhaliana, el "odio impotente" que es ante todo un "odio así mismo" (16). A diferencia de Rawls para quién la envidia sería sólo un problema psicológico pasible de ser mitigado por las condiciones de equidad, Dupuy hace de la envidia ese componente irracional que nada ni nadie puede reducir y que por ende oficia de punto ciego sobre el que se levanta la teoría rawlsiana. Al mismo tiempo, sin embargo, el ojo de la envidia permite para Dupuy desencadenar la dinámica especular y con ella la posibilidad de un pasaje a una suerte de "deseo mimético" que regula el funcionamiento de las sociedades desacralizadas, como las modernas, cuando no hay el factor exterior que indique la valorización de las cosas.

Si el anverso de la justicia es en Freud la envidia primaria, también se podrá decir con Jean- Pierre Dupuy que los principios de la teoría de la justicia de Rawls en su empeño por eliminarla justifican el sacrificio. Aun cuando el sacrificio no necesariamente se torne en muerte - anota Dupuy -, el esbozo de una lógica sacrificial se lee en la disminución de la utilidad de un individuo en orden a incrementar la utilidad del conjunto, pues "la igualdad, nuestra pasión natural, es magnífica en los grandes corazones, pero para las almas estrechas, es simplemente envidia" (17).

Las notas irónicas que Germán García irá hilvanando en su "Curso de las pasiones", leyendo a Dupuy dibujan el emplazamiento de ese "arbitra- rio primero" que con Lacan podemos llamar lo real, el que no se reduce ni la "lotería genética", ni la condición social, aunque allí pudiera tomar cuerpo, real que intenta ser organizado por el kantismo del sistema rawlsiano subordinando el bienestar a lo justo. Será el expediente de las pasiones, calibrado por Dupuy en El sacrificio y la envidia, lo que pondrán de relieve la irreductible discordia entre las exigencias del individuo y del mercado y las posibilidades de la equidad. Como se recordará Jacques Lacan había impugnado la existencia de una "justicia distributiva del goce" en su Seminario de 1972, -un año después de la edición del libro de John Rawls-, aunque nada indique que esta impugnación pueda ser confundida con la exigencia de una justicia distributiva de los "bienes" de la sociedad - como aclara García -, en ella se lee la imposibilidad de una regulación política del goce que encarnado en el elemento pasional se demuestra inintegrable, renuente a la lógica de los intercambios, y refractario al cálculo de valor, lo que desestima cualquier posibilidad de fabricación de una nueva utopía de inspiración psicoanalítica (18).

Coda. Porque se trata en suma de las relaciones discordantes entre la justicia y lo justo, no se podrá pasar por alto la humorada con la que Lacan apunta a esa discordia como al pasar en el mismo Seminario: "la redondez se extrae de lo redondo, por qué no, la justicia de lo justo..." (19).

\section{Notas:}

(1) Forrester, John: "Justicia, envidia y psicoanálisis". Partes de guerra. El psicoanálisis y sus pasiones. Editorial Gedisa. Barcelona (2001).

(2) Freud, Sigmund: Psicología de las masas y análisis del yo. Amorrortu Editores. Tomo XVIII, (1998)

(3) Ibid., Pág. 115.

(4) Rawls, John: Teoría de la justicia. Fondo de Cultura Económica (2006)

(5) Ibid., Pág. 483.

(6) Ibid., Pág. 29.

(7) Braunstein, Néstor: "El padre primitivo al padre digitalizado. Del urvater al big brother". Freud: a cien años de Tótem y tabú. Siglo XXI. México. (2013). Pág. 92.

(8) Rawls, John: Teoría de la justicia. Fondo de Cultura Económica (2006) Pág. 487.

(9) Ibid., Pág. 31

(10) Lacan, Jacques: Seminario Libro 11. Los cuatro conceptos fundamentales. Editorial Paidós. Buenos Aires. (1990). Pág. 122.

(11) Rawls, John: Teoría de la justicia. Fondo de Cultura Económica (2006). Pág. 487.

(12) Para un examen de esta comparación consultar en este número de Re- vista Estrategias: Joan Cojec, "Justicia amarga envidia liberal". Imaginemos que la mujer no existe. Fondo de cultura económica. Buenos Aires (2006). (13) Rawls, John: Teoría de la justicia. Fondo de Cultura Económica (2006). Pág. 487.

(14) Dupuy, Jean-Pierre: El sacrificio y la envidia. El liberalismo frente a la justicia social. Editorial Gedisa. Barcelona (1998).

(15) García, Germán: El curso de las pasiones. Curso breve de enero Cuadernillo del Centro Descartes, transcripción Alicia Alonso. (1999).

(16) Dupuy, Jean-Pierre: El sacrificio y la envidia. El liberalismo frente a la justicia social. Editorial Gedisa. Barcelona (1998). Pág. 198.

(17) Dupuy, Jean-Pierre: El sacrificio y la envidia. El liberalismo frente a la justicia social. Editorial Gedisa. Barcelona (1998). Pág. 71.

(18) García, Germán: "No hay regulación política del goce" - Intervención. El psicoanalista y escritor Germán García debatió con los utopistas clásicos en el ciclo Plácidos Domingos en junio de 2001. Publicado por Revista Ramona. Bueno Aires, marzo 2002. (Consultar versión online: http://www.ramona.org.ar/files/r21-22.pdf )

(19) Jacques Lacan, Seminario Libro 20. Aun. Editorial Paidós. Buenos Aires. (1991). Pág. 29. 